\title{
Stenting in type A aortic dissection: fantasy or reality?
}

\author{
Amer Harky ${ }^{1}$, Ahmed Al-Adhami \\ ${ }^{1}$ Department of Vascular Surgery, Countess of Chester Hospital, Chester, UK; ${ }^{2}$ Department of Cardiothoracic Surgery, Golden Jubilee National \\ Hospital, Glasgow, UK \\ Correspondence to: Amer Harky, MBChB, MRCS. Department of Vascular Surgery, Countess of Chester Hospital, Chester, UK. Email: aaharky@gmail.com.
}

Received: 11 June 2018; Accepted: 03 July 2018; Published: 03 August 2018.

doi: 10.21037/jovs.2018.07.09

View this article at: http://dx.doi.org/10.21037/jovs.2018.07.09

\section{What is the evidence?}

Open surgical repair of the ascending aorta in ATAAD is the gold standard method of management (1). With improvement in perioperative management and earlier surgical intervention secondary to advances in diagnostic imaging, the mortality rate has dramatically reduced. Reported mortality rates vary between $10 \%$ and $35 \%$ depending on centre volume and surgeon experience (2-4). Nevertheless, it is well understood that not all patients presenting with ATAAD are deemed suitable for emergent open surgery and hence the importance of evaluating alternative therapies such as endovascular stenting (5). Up to $30 \%$ of patients presenting with ATAAD are considered high risk for open surgical repair and constitute a mortality rate of over $50 \%$. In many instances such patients are deemed inoperable due to multiple medical comorbidities or pre-existing poor quality of life $(6,7)$. However, one must consider that patients managed medically exhibit a mortality rate of $90 \%$ at 1 month and open repair serves the optimum life-saving procedure in the majority of patients with satisfactory clinical outcomes (8-10).

\section{Will endovascular repair techniques supersede open surgical repair?}

Implementation of endovascular repair techniques in the treatment of abdominal aortic aneurysms, thoracic aortic aneurysms and type B aortic dissection is well established in the literature (11). However, evidence supporting the use of endovascular stenting in the context of type A aortic dissection is lacking and is limited to case series and selected centre experiences $(5,12,13)$.

Eggebrecht et al. $(12,14)$ were among the first groups to bring the use of endovascular stenting in type B thoracic aortic dissection to the forefront internationally. They reported an $11 \%$ mortality rate and $11 \%$ incidence of nonfatal perioperative complications among 38 patients that underwent stent-graft placement for either acute or chronic descending aortic dissection. In a later study by Ronchey et al. (5), outcomes of 37 patients that presented with ATAAD were analyzed, 28 of whom underwent open repair and four patients underwent endovascular stenting as they were deemed high risk for open repair and technically suitable for endovascular repair. They reported a technical success rate of $100 \%$, freedom from re-intervention of $100 \%$ at median follow up of 15 months, and 3 patients with complete thrombosis of the false lumen in the ascending aorta.

In an observational study, Vallabhajosyula et al. (13) evaluated the use of endovascular stenting of the ascending aorta in two patients with ATAAD and four with pseudoaneurysms of the ascending aorta. They were able to achieve appropriate stent deployment in five patients and one patient had persistent endoleak not amenable for further repair. At time of follow up at 12 months only one patient had a residual endoleak. Although there were no cases of operative mortality, two patients died at 6 and 27 months following discharge from non-aortic causes. The authors concluded that stenting of the ascending aorta is feasible in high risk patients but possess many challenges and requires high level of technical skills, focused expertise and a dedicated team effort. Two years later Tsilimparis et al. (15), performed a retrospective analysis of 10 patients that underwent endovascular stenting of the ascending aorta through a transfemoral approach (dissection $=5$, aneurysm $=4$, fixation of dislocated aortic valve $=1$ ). There was one death $(10 \%)$ within 30 days of surgery and two (20\%) patients required re-interventions for sustained 


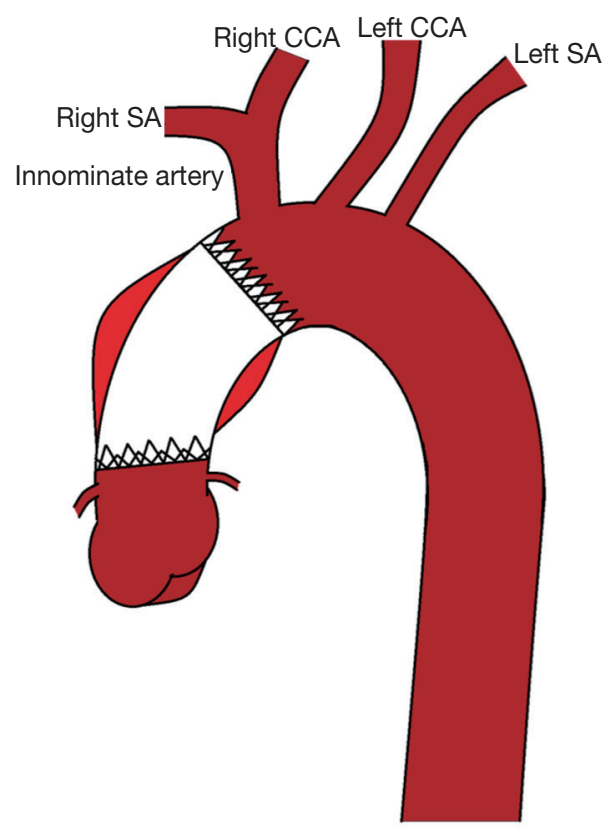

Figure 1 A diagram showing deployment of endovascular stent for type A aortic dissection and its related anatomical landmarks. CCA, common carotid artery; SA, subclavian artery.

endoleaks. Survival rate at 10 months reduced to $70 \%$ with one patient dying as a result of graft infection. Use of grafts graft in such cases where open repair is not indicated or in patients falling within the inoperable category. Those results were further supported by the findings of Li et al. (16) in their focused study on ascending aortic dissection. They studied outcomes in 15 patients undergoing endovascular stent-graft repair who were not eligible for open surgical intervention. Technical success was achieved in all patients with no operative mortality and $100 \%$ survival rates at median follow up of 72 months. Reintervention rate however was $27 \%$. Moreover, it is important to note that the majority of procedures were not performed in the emergency setting (mean of 25.5 days between ATAAD diagnosis and stent deployment).

Finally, Nienaber et al. (17) recently reported the outcomes of endovascular stenting in 12 patients with ATAAD from three international centres. Technical success was achieved in $91.7 \%$ while no cases of early mortality. All-cause mortality at 3 years was $33.3 \%$. Based on such data, the authors recommend stenting of ascending aorta; however more technical feasibility studies and large sample studies are required confirming this benefit.

\section{What are the limitations of endovascular stenting in ATAAD?}

ATAAD presents unique challenges to endovascular stenting. Firstly, intimal tears must be covered, with a safe surrounding landing zone, and their locations can therefore pose difficulties particularly in its terms of their proximity to the aortic valve and coronary ostia (Figure 1). Such proximity to the landing zones increases the risk of aortic valve dysfunction and disruption of coronary circulation with resultant coronary ischaemia (11). Furthermore, the anatomy of the arch and great vessels can make finding a sufficient safe landing zone difficult and technically demanding (12). Moreover, the risk of introducing a new intimal tear during stent placement in what is already a fragile aorta exists and is associated with increased morbidity and mortality (15). Given the high rate of endoleaks after any form of aortic stenting, the presence of residual endoleaks is particularly problematic in the fragile newly dissected ascending aorta can potentially result in extension of aortic dissection (11). Another limitation is the nature of the stent graft itself and its availability. In most cases of thoracic and abdominal aortic aneurysms, the stent graft is custom made and their immediate availability for use in patients with ATAAD is therefore compromised (17).

\section{Conclusions}

There is a lack of sufficient evidence to support the use of endovascular stenting in the in the setting of ATAAD due to both technical and stent-graft related limitations. The current literature only comprises of small case series and observational studies that are inadequately powered to provide conclusive recommendations. Open repair will therefore remain the gold standard method of managing ATAAD. A trial of endovascular stenting is warranted in patients considered surgically inoperable due to prohibitive comorbidities to help reduce the morbidity and mortality associated with untreated ATAAD.

\section{Acknowledgments}

Funding: None.

\section{Footnote}

Provenance and Peer Review: This article was a free submission to the editorial office, Fournal of Visualized 
Surgery. The article did not undergo external peer review.

Conflicts of Interest: Both authors have completed the ICMJE uniform disclosure form (available at: http://dx.doi. org/10.21037/jovs.2018.07.09). The authors have no conflicts of interest to declare.

Ethical Statement: The authors are accountable for all aspects of the work in ensuring that questions related to the accuracy or integrity of any part of the work are appropriately investigated and resolved.

Open Access Statement: This is an Open Access article distributed in accordance with the Creative Commons Attribution-NonCommercial-NoDerivs 4.0 International License (CC BY-NC-ND 4.0), which permits the noncommercial replication and distribution of the article with the strict proviso that no changes or edits are made and the original work is properly cited (including links to both the formal publication through the relevant DOI and the license). See: https://creativecommons.org/licenses/by-nc-nd/4.0/.

\section{References}

1. Uchida N, Shibamura H, Katayama A, et al. Operative strategy for acute type a aortic dissection: ascending aortic or hemiarch versus total arch replacement with frozen elephant trunk. Ann Thorac Surg 2009;87:773-7.

2. Bashir M, Harky A, Fok M, et al. Acute type A aortic dissection in the United Kingdom: Surgeon volumeoutcome relation. J Thorac Cardiovasc Surg 2017;154: 398-406.e1.

3. Tsai TT, Trimarchi S, Nienaber CA. Acute aortic dissection: perspectives from the International Registry of Acute Aortic Dissection (IRAD). Eur J Vasc Endovasc Surg 2009;37:149-59.

4. Bonser RS, Pagano D, Haverich A, et al. Controversies in Aortic Dissection and Aneurysmal Disease. London: Springer-Verlag London, 2014:1-457.

5. Ronchey S, Serrao E, Alberti V, et al. Endovascular stenting of the ascending aorta for type A aortic dissections in patients at high risk for open surgery. Eur J Vasc Endovasc Surg 2013;45:475-80.

doi: 10.21037/jovs.2018.07.09

Cite this article as: Harky A, Al-Adhami A. Stenting in type A aortic dissection: fantasy or reality? J Vis Surg 2018;4:161.
6. Centofanti P, Flocco R, Ceresa F, et al. Is surgery always mandatory for type A aortic dissection? Ann Thorac Surg 2006;82:1658-63; discussion 1664.

7. Rampoldi V, Trimarchi S, Eagle KA, et al. Simple risk models to predict surgical mortality in acute type A aortic dissection: the International Registry of Acute Aortic Dissection score. Ann Thorac Surg 2007;83:55-61.

8. Malvindi PG, Modi A, Miskolczi S, et al. Open and closed distal anastomosis for acute type A aortic dissection repair. Interact Cardiovasc Thorac Surg 2016;22:776-83.

9. Vohra HA, Modi A, Barlow CW, et al. Repair of acute type A aortic dissection: results in 100 patients. Asian Cardiovasc Thorac Ann 2012;20:160-7.

10. Lai DT, Robbins RC, Mitchell RS, et al. Does profound hypothermic circulatory arrest improve survival in patients with acute type A aortic dissection. Circulation 2002;106:I218-28.

11. Shah A, Khoynezhad A. Thoracic endovascular repair for acute type A aortic dissection: operative technique. Ann Cardiothorac Surg 2016;5:389-96.

12. Nienaber CA, Skriabina V, Schareck W, et al. To stent or not to stent aortic dissection: good news for a chosen few, but who? Eur Heart J 2005;26:431-2.

13. Vallabhajosyula P1, Gottret JP, Bavaria JE, et al. Endovascular repair of the ascending aorta in patients at high risk for open repair. J Thorac Cardiovasc Surg 2015;149:S144-50.

14. Eggebrecht H, Herold U, Kuhnt O, et al. Endovascular stent-graft treatment of aortic dissection: determinants of post-interventional outcome. Eur Heart J 2005;26:489-97.

15. Tsilimparis N, Debus ES, Oderich GS, et al. International experience with endovascular therapy of the ascending aorta with a dedicated endograft. J Vasc Surg 2016;63:1476-82.

16. Li Z, Lu Q, Feng R, et al. Outcomes of Endovascular Repair of Ascending Aortic Dissection in Patients Unsuitable for Direct Surgical Repair. J Am Coll Cardiol 2016;68:1944-54.

17. Nienaber CA, Sakalihasan N, Clough RE, et al. Thoracic endovascular aortic repair (TEVAR) in proximal (type A) aortic dissection: Ready for a broader application? J Thorac Cardiovasc Surg 2017;153:S3-S11. 